\author{
Military Technical College \\ Kobry El-Kobbah, \\ Cairo, Egypt
}

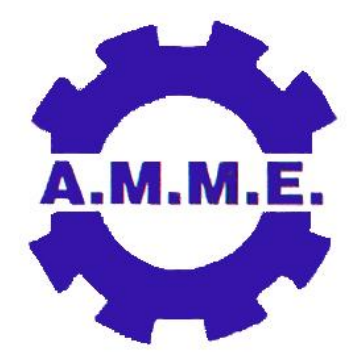

$14^{\text {th }}$ International Conference on

Applied Mechanics and

Mechanical Engineering AMME-14

\title{
ELECTRONIC PREDICTION OF VEHICLE MOBILITY ON DEFORMABLE SOIL
}

\author{
By \\ $\begin{array}{lll}\text { H. Ragheb* N. Girgis * S. Hegazy* } & \end{array}$
}

\section{Abstract:}

Mobility is the ability to move freely and rapidly over the terrain of interest to accomplish varied off-road objectives. The vehicle weight and its footprint determine the resultant ground pressure that the vehicle imparts on the soil. The soil strength, coupled with the ground pressure, determines vehicle cone index, $\mathrm{VCl}$, which is the key for vehicle mobility.

The cone penetrometer is designed to give an index of soil strength where the operator will quickly shift his vision from the rod at the ground to the dial at the proper moment, meanwhile maintaining a constant penetration rate; this may cause an error in reading and recording the results. A comparison of rating cone index $\mathrm{RCl}$ with the vehicle cone index $\mathrm{VCl}$ indicates whether the vehicle can negotiate the given soil condition for a given number of passes.

In this paper an adaptation has been made to the standard cone penetrometer to become an electronic device. The proving ring is replaced with a load cell, and the depth of penetration in soil is measured with displacement transducer sensor. Then the applied force and the sinkage are automatically recorded on a data storage module and processed to obtain the rating cone index $(\mathrm{RCl})$ of different soil. Three interfacing circuits to amplify the out voltage from load cell, displacement transducer and site number selector are designed. In the control unit, the microcontroller is coupled to an EEPROM (Electrically Erasable Programmable Read-Only Memory)to store the measured load and sinkage data. It has a capacity sufficient to store the measured data from different 12 sites. For each of them, 256 samples are sensed during test.

\section{Keywords:}

Vehicle mobility, Soil testing, Vehicle cone index, Cone penetrometer 


\section{Introduction:}

\section{Egyptian Armed Forces}

Vehicle mobility is the overall capability of a vehicle to move from place to place while retaining its ability to perform its primary mission [1]. Terrain trafficability means the ability of terrain to support the passage of vehicles [1]. There are a lot of studies and articles in existence that deal with components related to tractability. Hintze [2], Rounsevell [3] and Earl [4] have set out to predict soil strength with the aid of climatic data. Davis and Laut [5], Saarilahti [6] have estimated the terrain trafficability and soil strength. Birkel [7] took into account the interaction between the terrain and the vehicle. Orava [8] used raster analysis to determine terrain trafficability as needed for planning military activities, but his application included only terrain parameters and did not contain the attributes of the vehicle, and therefore it could not be used to solve routing problems.

The mobility of a vehicle is influenced by three main parameters; vehicle parameters, soil parameters and environmental parameters (Climate conditions and driver's skill). The vehicle parameters; vehicle performance, geometric configuration, vehicle construction and economy of operation have considerable influence on vehicle mobility [9]. The soil parameters affecting vehicle mobility include; behavior under loading, transient and permanent parameters [10-12]

Jody et al [10] explained how $\mathrm{VCl}$ is measured, and compared with different methods of predicting $\mathrm{VCl}$ for one-pass performance of wheeled vehicles in fat clay soils. It is further clarified that MMP (mean maximum pressure) should not be compared with VCl. They modified and developed existing relationships for using MMP to predict VCl1 for wheeled vehicles in clay. Therefore the resulting relationships allow comparison between $\mathrm{MMP}$ and $\mathrm{MI}$ in terms of their ability to predict $\mathrm{VCl}$. A vehicle cone index is obtained using vehicle parameters. A comparison of the $\mathrm{VCl}$ and the soil $\mathrm{RCl}$ will result in a prediction of whether the vehicle is mobile or not (GO/NO GO) in a particular soil.

The experimental testing of soil trafficability has been carried out using developed cone penetrometer. An adaptation has been made to the cone penetrometer, the proving ring is replaced with a load cell, and the depth of penetration is measured with displacement transducer sensor. The output of the device is then automatically recorded on a data storage module. Using the cone penetrometer, rating cone index $(\mathrm{RCl})$ is a measure of the soil response to repetitive loads. A vehicle cone index $(\mathrm{VCl})$ is obtained using vehicle parameters; weight, dimensions, engine, and transmission factors. A comparison of the $\mathrm{VCl}$ and the soil $\mathrm{RCl}$ will result in a prediction of whether the vehicle is mobile or not (GO/NO GO) in a particular soil.

\section{Developed cone penetrometer:}

When using cone penetrometer, operator will face many difficulties during measuring process such as:

- Keeping the shaft vertical to minimize eccentric loading of the proving ring.

- Take a dial reading just as the base of the cone becomes flush with the ground surface. 
- Penetration rate should be slow and steady (approximately $30 \mathrm{~mm} / \mathrm{sec}$ ).

- Recording the readings of both load and sinkage should be with the aide of another operator or it may be convenient to make two cone penetrometer readings, stop the penetration to record the readings, resume the penetration to obtain two additional readings, and then stop to record.

- The operator cannot take the GO/NO GO decision without processing and some calculations.

In order to obtain accurate measurements, a set of modifications for the standard cone penetrometer have been proposed. They are summarized as follows:

- The proving ring and dial gauge used for measuring the applied load are replaced by a load cell.

- A displacement sensor is used instead of the visual observation of sinkage on the cone penetrometer rod.

- Both outputs of the load cell and the displacement transducer are fed to an electronic control unit. This unit fulfills two tasks:

(a) Recording the outputs of the two sensors during test.

(b) Sending the recorded data to computer through its serial port for further data processing.

- The control unit has LED display for indicating the measuring, or data sending, time.

- It has additional LED display to indicate the GO/NO GO decision in field.

- $\quad$ A "U" shape arrangement is added to the base of the cone penetrometer to insure the perpendicularity of the cone to ground and zeroing the displacement transducer reading with the base of the cone.

\subsection{Load Measurement:}

The load is measured using load cell, Philips PR 6246 (range 100-500kg) universal compression / tension load cell. The compact S-type design assures easy and secure installation. Error! Reference source not found.1) shows the S-Type Load cell, which depends on the idea of differential type load sensors, with its connecting circuit. A calibration process has been done to the load cell using different loads 


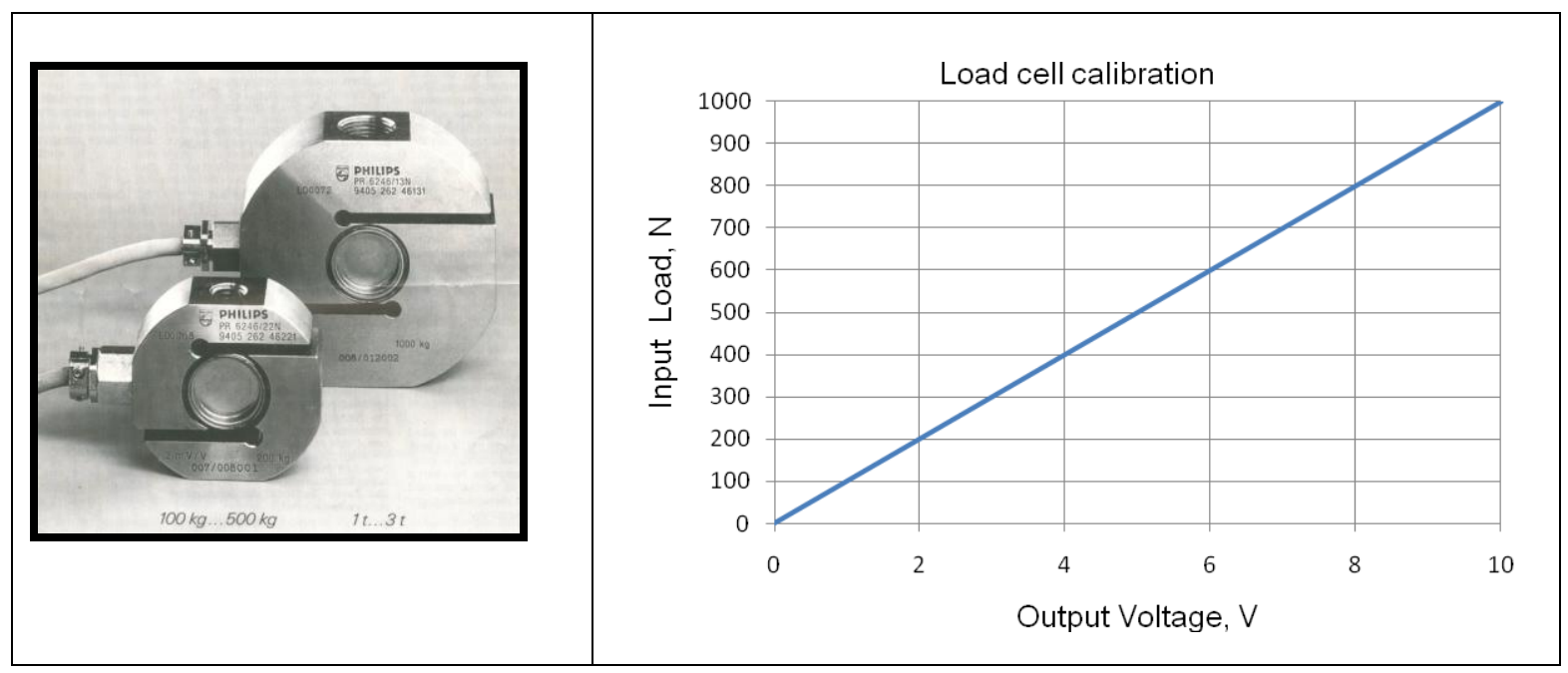

Figure (1): S type load cell control unit

\subsection{Sinkage Measurements:}

The sinkage is measured using displacement transducer, Fig. (2), OMEGA'S® LD300 displacement transducer is essentially miniature transformer, has one primary winding, two symmetrically wound secondary coils, and an armature core that is free to move along the linear axis in precision bearing guides. A push rod connects the monitored component to the armature core, such that the displacement of that component moves the core off center. A calibration process has been done to the displacement transducer.
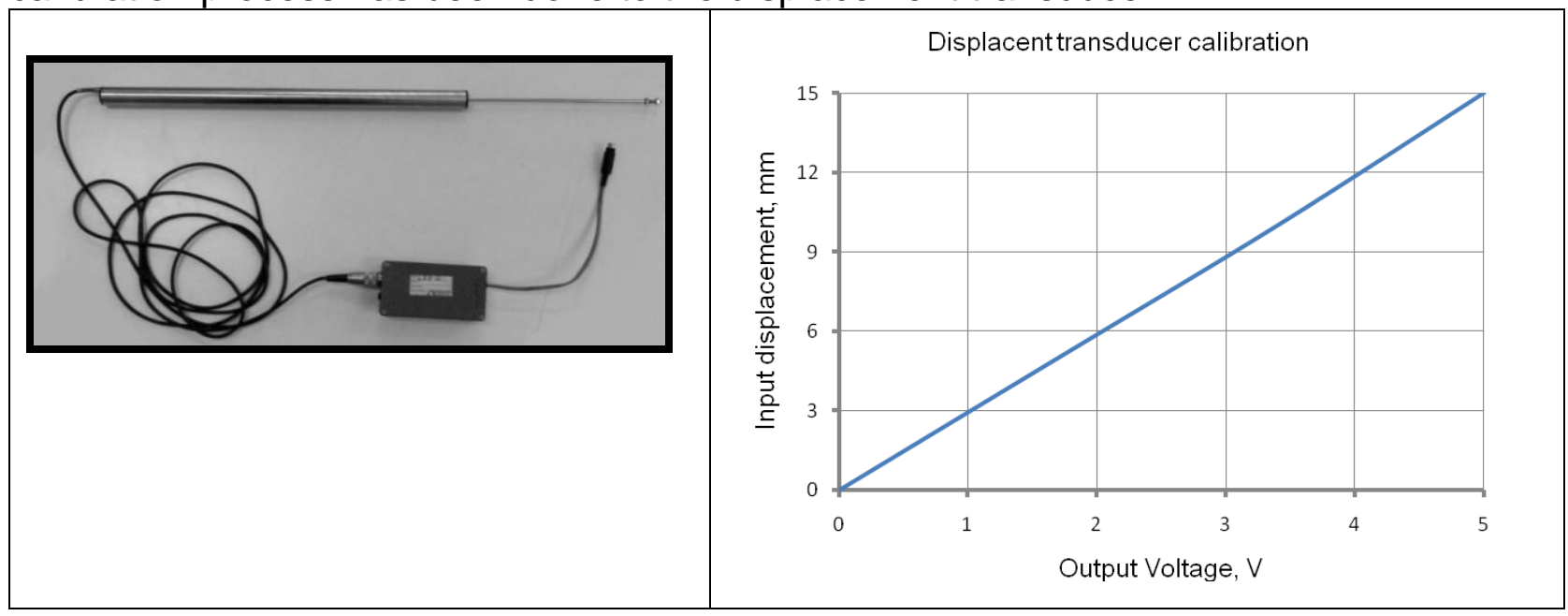

Figure (2): Displacement transducer

\subsection{Electronic Control Unit:}

The electronic control unit of the proposed electronic cone penetrometer operates in two modes; "measuring mode and send mode". In measuring mode, the outputs of the load and displacement sensors, are stored in a non volatile memory in control unit. In send mode, the stored data is sent to computer in the form suitable to be accepted by its serial port.

The main element of electronic control unit is a microcontroller coupled to an EEPROM to store the measured values. The unit block diagram shown in Error! Reference source not 
found.3) Consists of Power supply circuit, Microcontroller circuit coupled to an EEPROM, which is used as a non-volatile memory to store the measured load and sinkage data and Interfacing Circuits for load cell, displacement transducer, sight number selector switch and serial port of computer.

The used EEPROM has a capacity sufficient to store the measured data from different 12 sites. For each of them, 256 samples are sensed during test. The output analog voltages of the load and sinkage sensors are applied to the A/D converter included in the microcontroller. It converts them to the binary form such that their measured values during test can be stored in the EEPROM. A third analog voltage is fed from the site selector switch. From this $12-$ position rotary switch, a DC voltage is applied to the microcontroller. The magnitude of this voltage depends on the position of the switch handle, which assign the site number. The corresponding binary value is used to assign the site the data of which is sensed and stored or send to the computer. Three interfacing circuits are used to adapt the analogue voltages; from the load sensor, the displacement transducer, and from site number switch to the input voltage range of the microcontroller analog to digital converter.

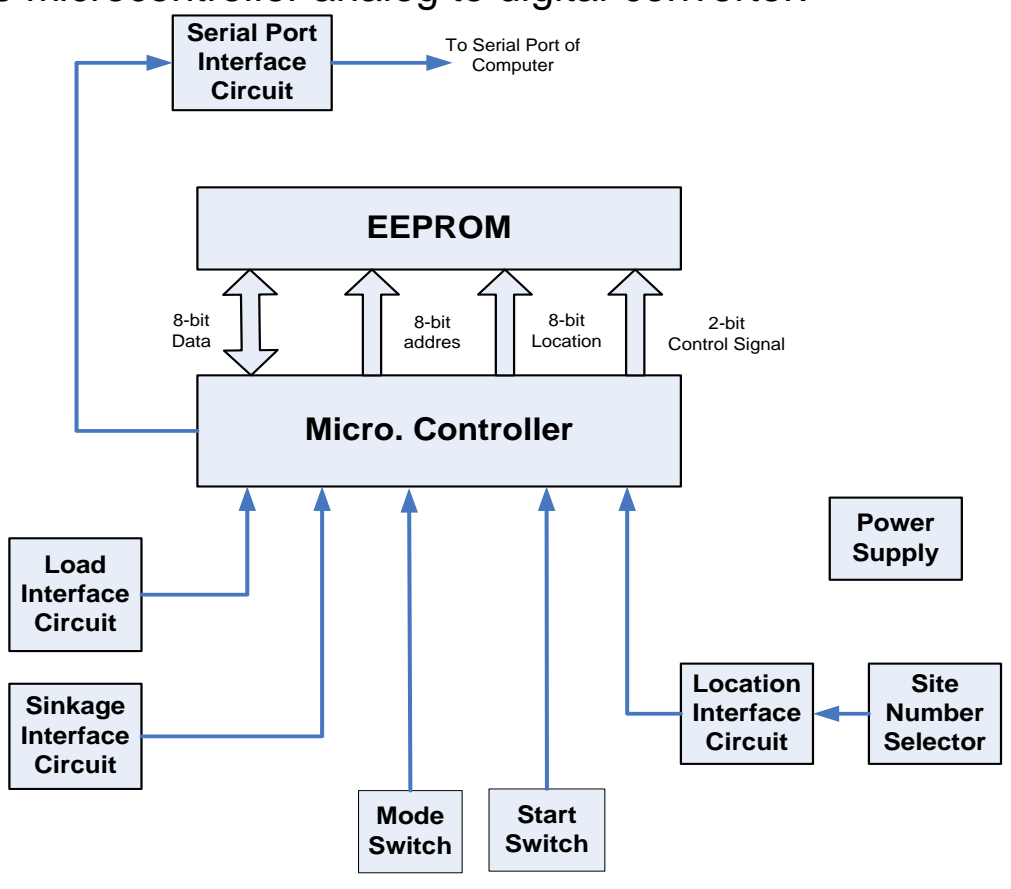

Figure (3-a): Electronic Control Unit Block Diagram 


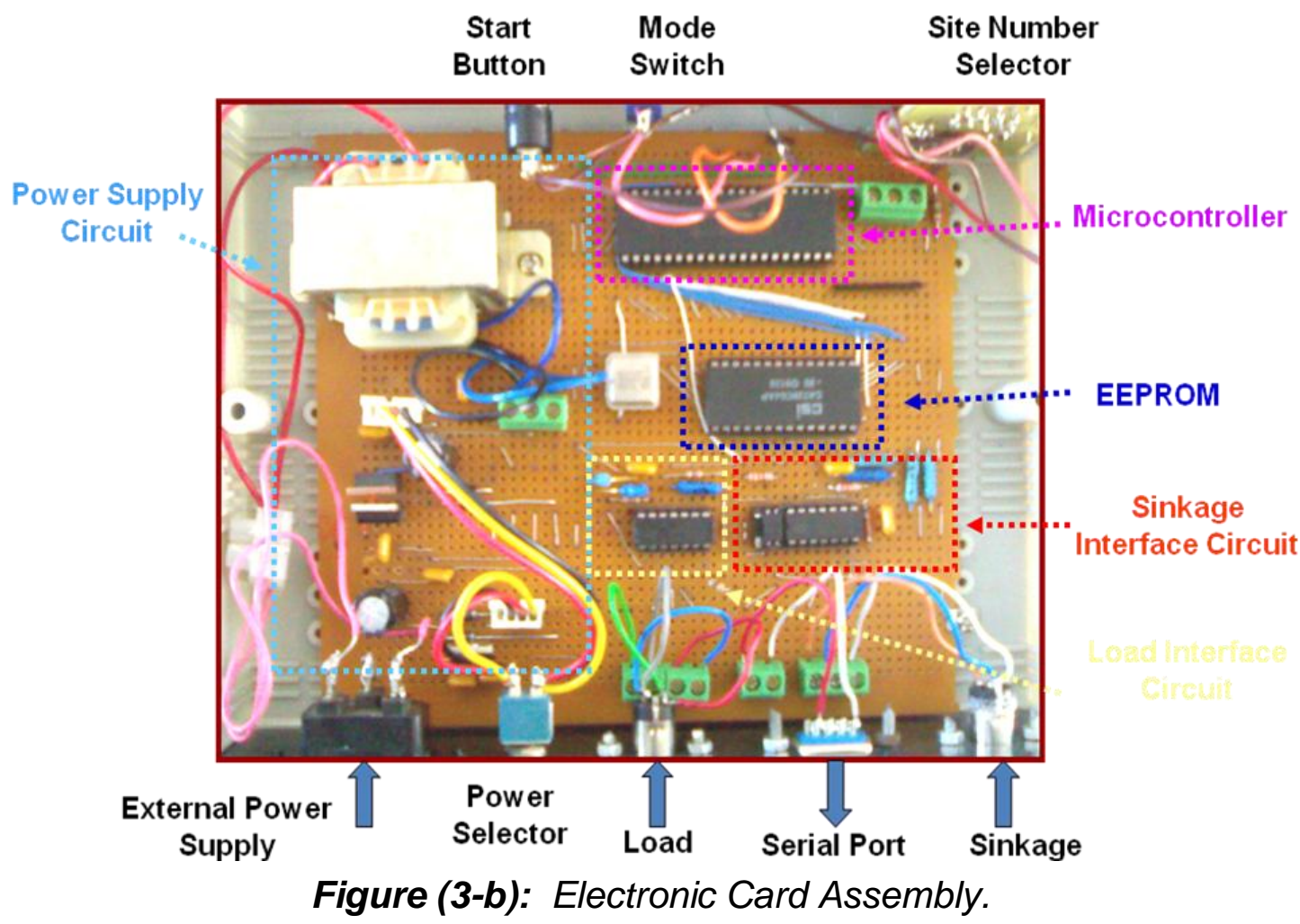




\section{(A) Power Supply Circuit}

Power supply circuit is designed to feed the electronic circuit with 10 volt DC to feed the load cell and the displacement transducer and 5 volt DC and 9 volt DC to supply the used integrated circuits of the control circuit. These voltages are obtained using either external batteries, or using the $220 \mathrm{AC}$

\section{(B) Interfacing Circuits}

\section{1- Interfacing circuit for Load Cell:}

The function of this circuit is to amplify the differential output voltage of the load cell corresponding to the applied load on the cell. The output of this circuit is adjusted to vary from $0-5 \mathrm{~V}$ DC corresponding to the expected range of load during measuring $(0: 100 \mathrm{Kg})$. The circuit diagram based on IC type LM324 is shown in Error! Reference source not found.4).

\section{2- Interfacing circuit for displacement transducer:}

The function of this circuit is to amplify the sensor output voltage and to shift its DC component such that the resulting output voltage changes from 0:5V DC as the sensor plunger moves between its two extreme positions. The circuit diagram based on the Op Amp type LM 324 is shown in Error! Reference source not found.5).

\section{3- Interfacing circuit of the site number selector:}

The site number selector is a rotary switch with 12 positions (corresponding to 12 different sites). The $5 \mathrm{~V}$ DC supply voltage is fed to a 12- resistor voltage divider. According to the position of the rotary switch, the voltage of one of the tapes between resistors is selected and applied to the microcontroller; which outputs a 4-bit binary value representing the site number. This means that the position of the rotary switch specifies the number of the site; the site selector circuit is shown in Error! Reference source not found.6).

\section{4- Interfacing circuit for serial port:}

If the start button is bushed while the mode switch is in the position "Send", the microcontroller outputs a stream of serial data (512 bytes) arranged in pairs (load and displacement values) corresponding to the stored 256 measurement points. This data format is suitable to be received by the computer serial port. The serial port interfacing circuit is shown in Error! Reference source not found.7). It is based on coupler which insures the conversion of the TTL signal fed from the microcontroller to the levels used for computer serial port 


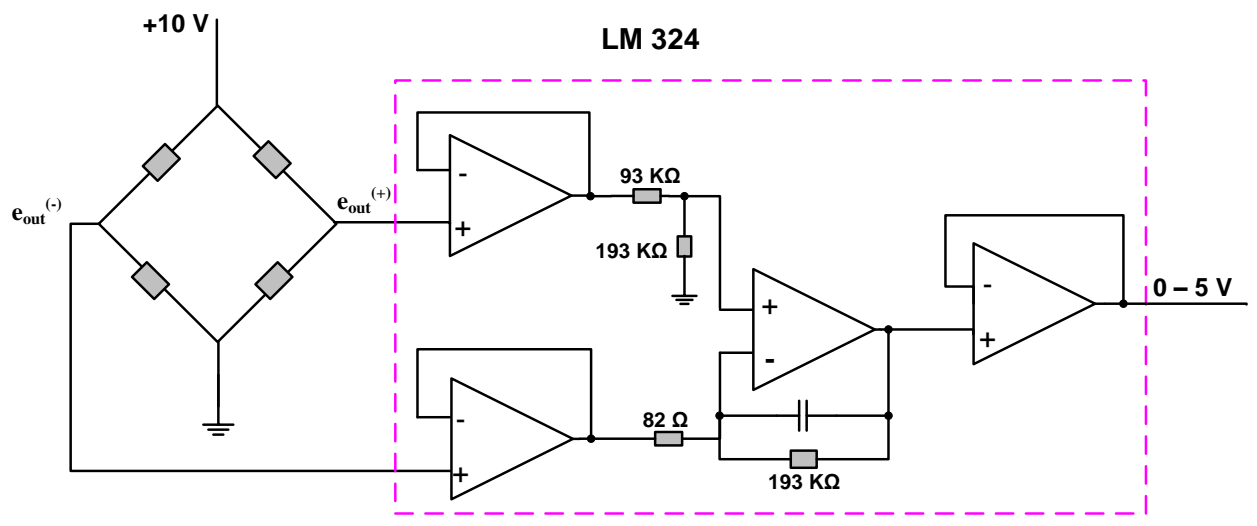

Figure (4): Interfacing circuit for load cell

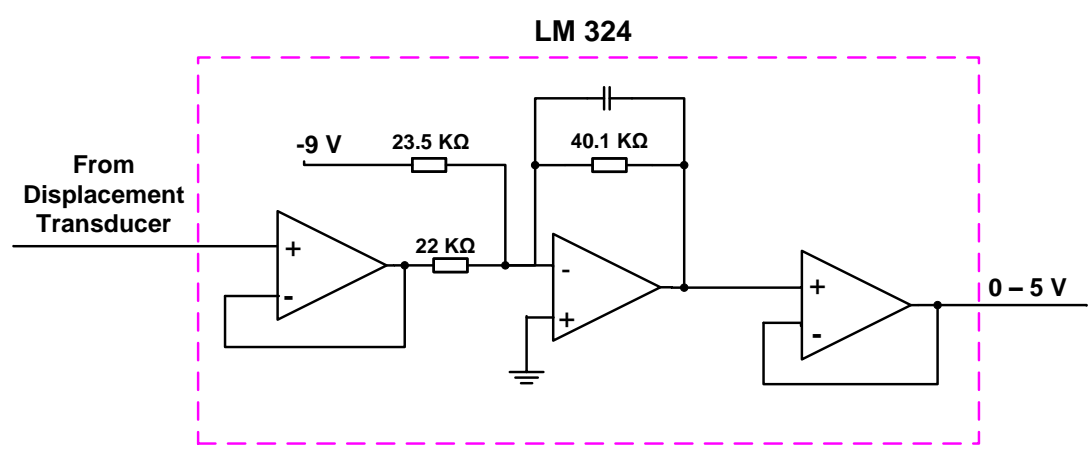

Figure (5): Interfacing circuit for Displacement transducer

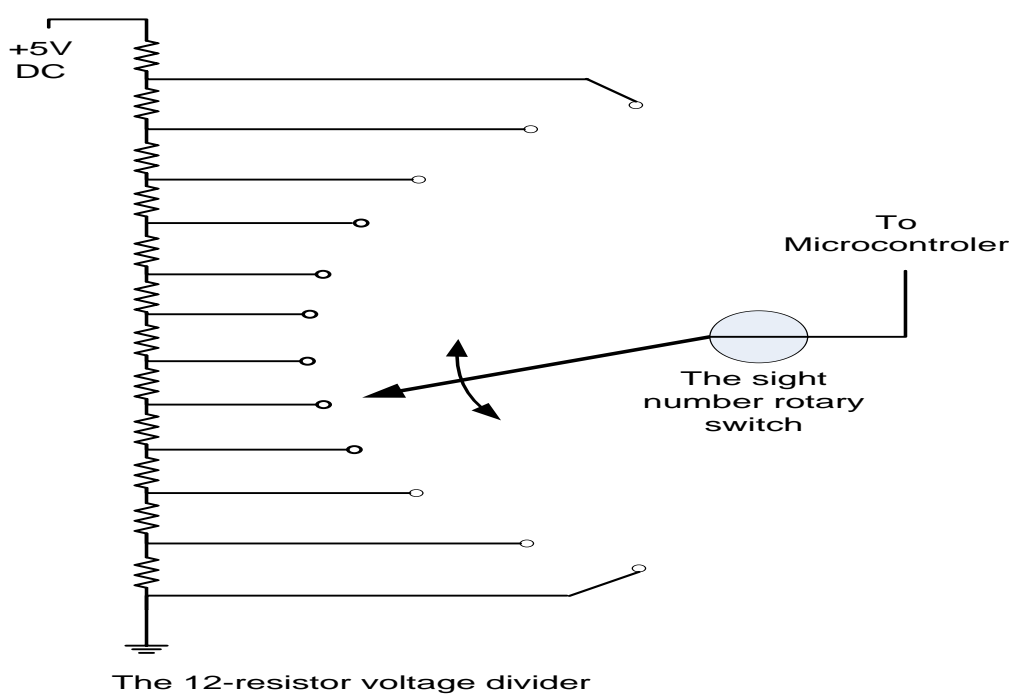

Figure (6): Interfacing circuit for Site number selector 


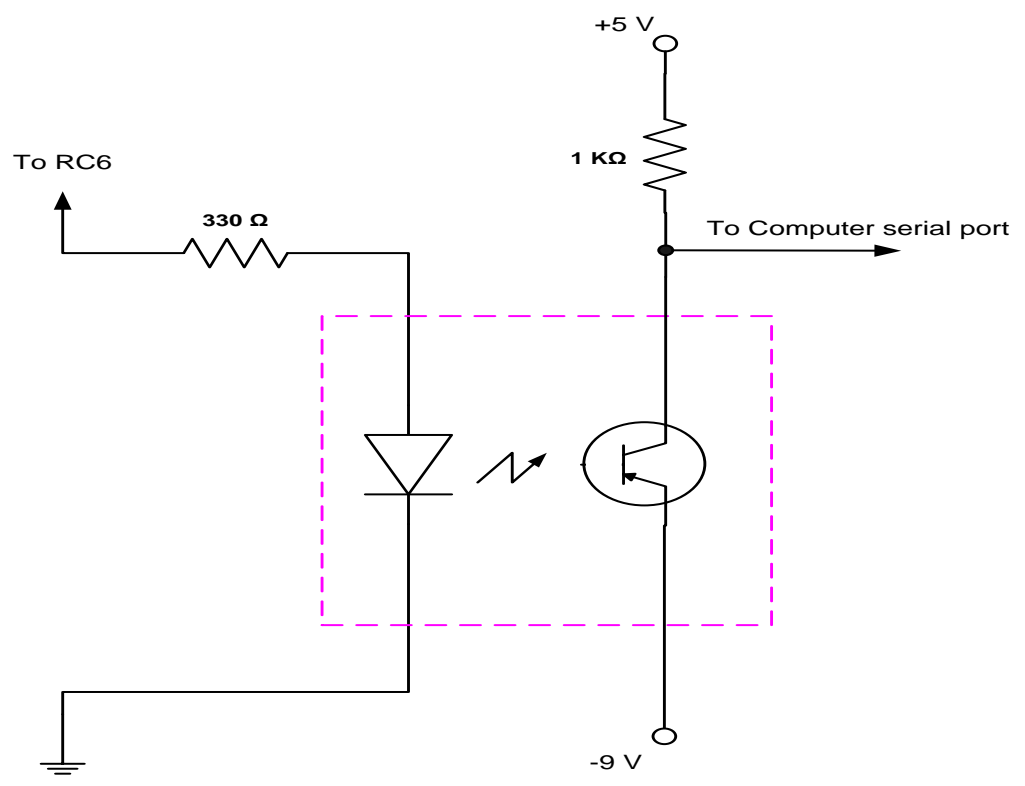

Figure (7): Interfacing circuit for Serial Port

\section{(C) Microcontroller circuit with the EEPROM}

The heart of this control circuit is a microcontroller coupled to an EEPROM. The microcontroller receives three analog voltages representing the output of the load cell, the output of the displacement transducer, and an analog voltage representing the measurement location. The microcontroller performs the following functions:

- In the measurement mode, it converts three input analog values to the binary form namely, the voltage from the load sensor, voltage from the displacement sensor, and voltage from selector switch which assign the number of site under test.

- A 4-bit binary code, representing the number of the site under test is fed to 4-lines of the EEPROM address lines.

- It controls the rate in which, the sensors outputs are sampled. The corresponding values are fed to the 8-bit data lines of the EEPROM.

- On the same time, it feeds, 8 address lines of the EEPROM by the binary code which represent the order of sample (among 256 sample) which data is fed to EEPROM data lines.

- Additional bit determines if the data fed to the EEPROM data lines are related to the load cell or the displacement sensor.

- In the send mode, microcontroller reads, in sequence, the data stored in EEPROM and send it serially, through an interface circuit, to a serial port of computer. The send data format, and baud rate is adjusted to suit the serial communication protocol.

\subsection{Assembly of the Proposed Cone Penetrometer Set}

To insure the vertical position of the cone shaft during measurement and zeroing the displacement transducer with the base of the cone, a "U" shape arrangement with rectangular base plate is made from sheet metal including two sliding bearings for smooth motion of the 
cone shaft, Fig. 8. For accurate measurement of sinkage, a wooden block is used for clamping the displacement transducer with the cone such that they will be parallel to each other and also for load cell fixation.

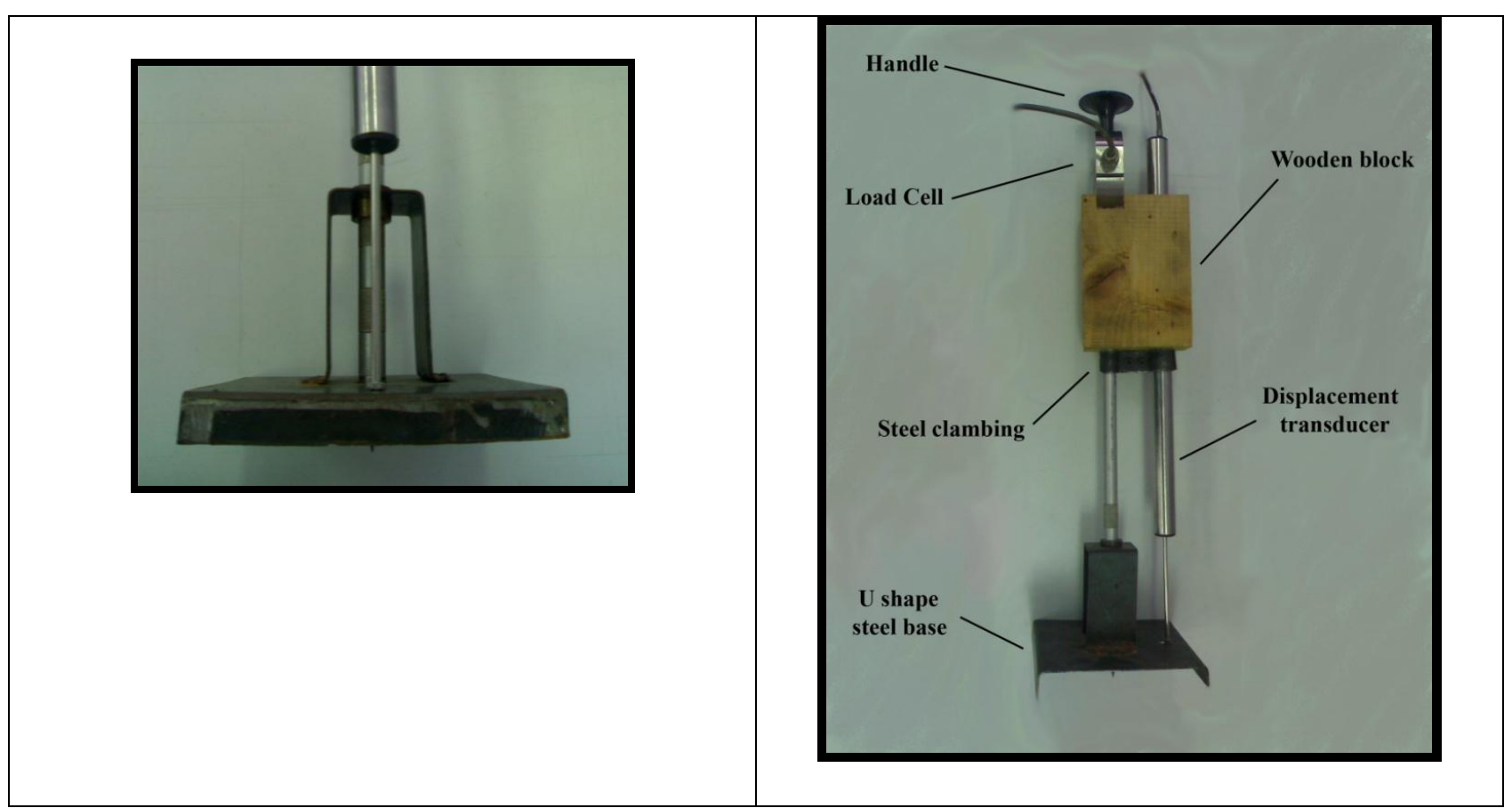

Figure (8): Adapted cone penetrometer

The front panel contains the site selector switch; mode switch, start button, and two indicating LED (electronic control unit operation LED, and GO/NO GO decision LED), Fig (9). The rear panel contains the external (220V) power supply input socket, the external / battery supply selector, socket for load cell cable, 9 pin D connector for serial communication, and socket for displacement transducer connection.

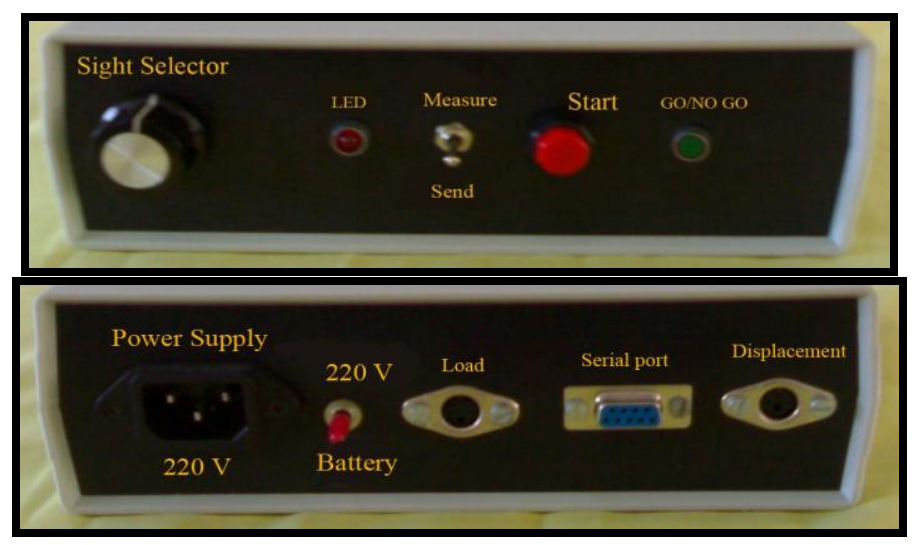

Figure (9): Front and rear panel of control box 


\section{Experimental Results of Field Soil Testing:}

The developed cone penetrometer was tested in different soil types such as sand and clay. The output results are shown in Fig. (10).

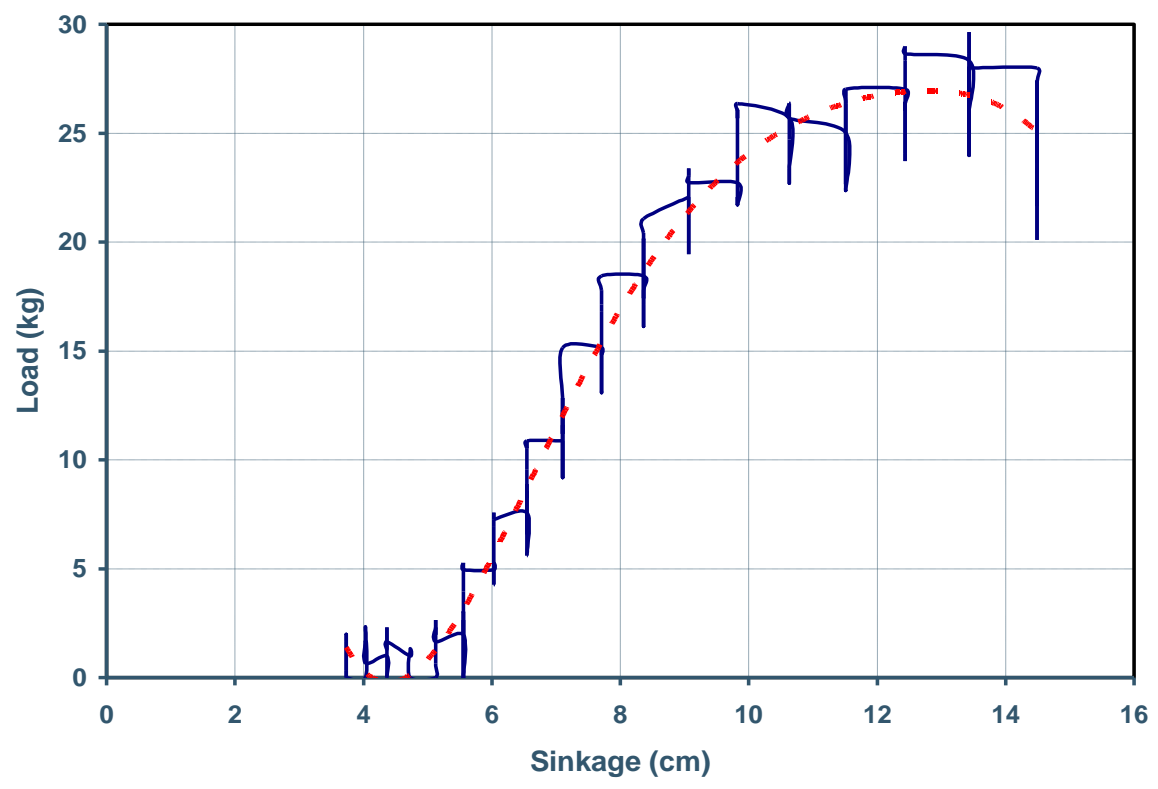

Figure (10-a): Load Sinkage relationship for clay

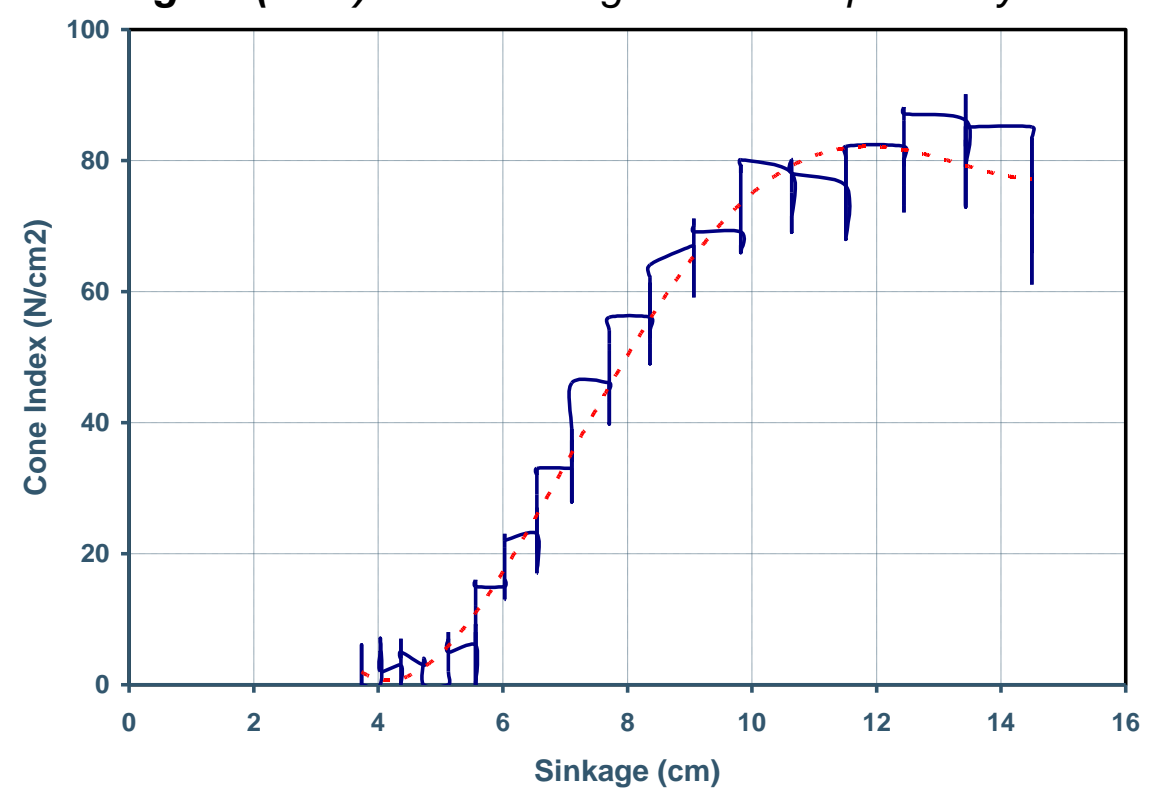

Figure (10-b): Cone Index Vs. sinkage for clay

\section{Analyses of Results:}

The processing of the output results for field soil testing using the developed cone penetrometer in two different areas are shown in Tables (1-3).

$\mathrm{VCl} 1$ and $\mathrm{VCl} 50$, was obtained using the following equations: 
For one pass, if $\mathrm{Ml} \leq 115$

$$
V C I_{1}=11.48+0.2 M I-\left(\frac{39.2}{M I+3.74}\right)
$$

And if $\mathrm{Ml}>115$

$$
V C I_{1}=4.1 \times M I^{0.446}
$$

And for 50 passes, for any MI value

$$
V C I_{50}=28.23+0.43 M I-\left(\frac{92.67}{M I+3.67}\right)
$$

And for $\mathrm{Ml}>40$

$$
\mathrm{VCI}_{50}=25.2+(0.454 \times M I) .
$$

Table (1): Vehicle Cone Index for different vehicles

\begin{tabular}{|c|c|c|c|}
\hline Parameter & (Gaz 69) & (Hummer M998) & (Zil 131) \\
\hline Specific power: $(\mathrm{hp} /$ Ton) & 26 & 43 & 13.5 \\
\hline Vehicle weight: $(\mathrm{kN})$ & 21 & 35 & 111 \\
\hline No. of tires. & 4 & 4 & 6 \\
\hline No. of axles. & 2 & 2 & 3 \\
\hline VCI 1 & 35.32 & 18.5 & 32.22 \\
\hline VCI 50 & 70.21 & 43 & 67.1 \\
\hline
\end{tabular}

Table (2): Trafficability test data for area No.1

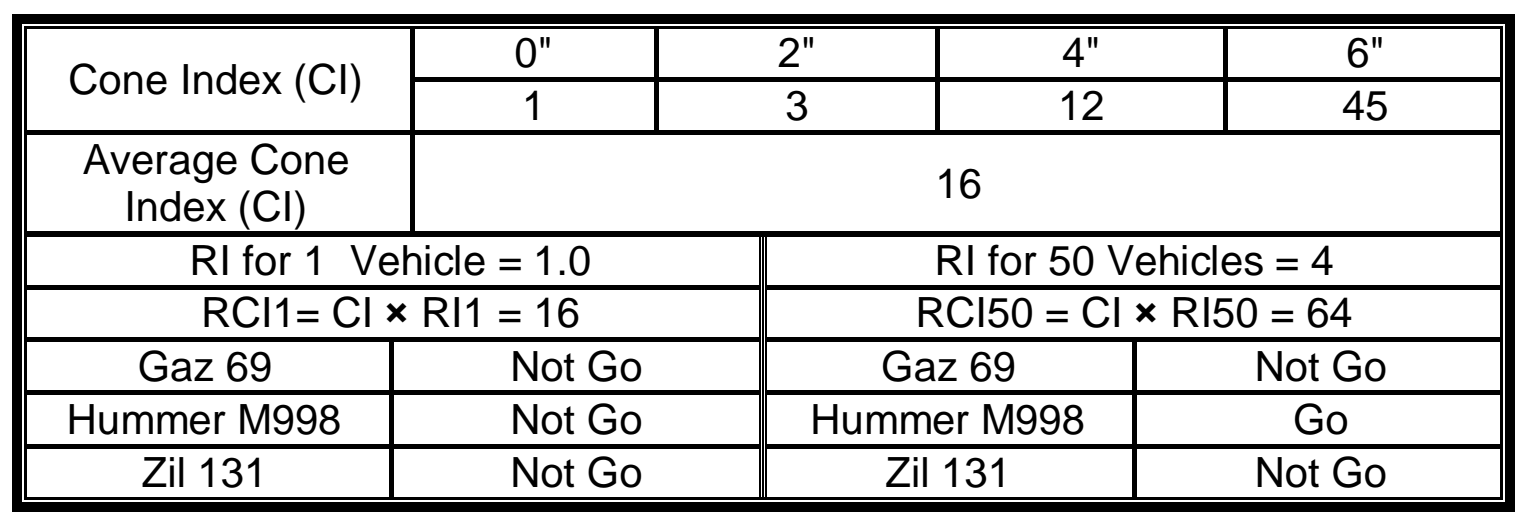


Table (3): Trafficability test data for area No.2

\begin{tabular}{|c|c|c|c|c|}
\hline \multirow{2}{*}{ Cone Index (Cl) } & $0 "$ & 2" & $4^{\prime \prime}$ & 6" \\
\hline & 3 & 10 & 10 & 102 \\
\hline $\begin{array}{l}\text { Average Cone } \\
\text { Index (CI) }\end{array}$ & \multicolumn{4}{|c|}{55} \\
\hline \multicolumn{2}{|c|}{ RI for 1 Vehicle $=1.0$} & \multicolumn{3}{|c|}{ RI for 50 Vehicles $=2.8$} \\
\hline \multicolumn{2}{|c|}{$\mathrm{RCl} 1=\mathrm{Cl} \times \mathrm{Rl} 1=55$} & \multicolumn{3}{|c|}{$\mathrm{RCl} \mid 50=\mathrm{Cl} \times \mathrm{RI} 50=154$} \\
\hline Gaz 69 & Go & & & Go \\
\hline Hummer M998 & Go & & 998 & Go \\
\hline Zil 131 & Go & & & Go \\
\hline
\end{tabular}

\section{Conclusions:}

The vehicle mobility for three different vehicles was evaluated. The mobility evaluation was based on vehicle parameters and soil testing in situ, using adapted cone penetrometer. A good measuring of soil strength using digital electronic cone penetrometer gives accurate results for soil strength and so correct decision for going on deformable soil

The adapted modifications in the standard cone penetrometer made it an easy field-testing equipment and gives accurate results for soil strength to predict off-road vehicle mobility. In addition, it adds the possibility to record the measured values, load and sinkage, in order to be send to computer, off line, for further processing or studying. The GO/NO GO decision is indicated by a light signal in the designed electronic control unit.

\section{References:}

[1] "International society for terrain-vehicle systems standards", Journal of Terramechanics, 1977, Vol. 14, No. 3, pp. 153 to 182.

[2] Hintze, D.," The prediction of soil strength with the aid of climatic data". In: ISTVS Eur 5. p. 17-24, 1990.

[3] Rounsevell MDA.,"A review of soil workability models and their limitations in temperate regions". Soil Use Manag 1993; 9 (1):15-21.

[4] Earl R.," Prediction of trafficability and workability from soil moisture". Soil Tillge Res 1997; 40:155-68.

[5] Davis JR, Laut P.,"An expert system to estimate trafficability in a remote region in of Australia". Al Appl 1989;3 (1):17-26.

[6] Saarilahti M. Ecomodel. In: Haarlaa R, Salo J, editors, University of Helsinki. 
Publication 31, February 2003; 2002. Available from:

http://ethesis.helsinki../julkaisut/maa/mvaro/publications/31/programs/

[7] Birkel PA., "Terrain trafficability in modelling and simulation". Technical paper SEDRIS; 2003. Available from: http://www.sedris.org/pr11trpl.htm, 2003-9-11.

[8] Orava E. Maastoanalyysi, "Terrain Analysis for Military Purpose”.,1999

[9] Emad Sayed Anbar, "Technical Evaluation of off-road Vehicle Mobility", MSC thesis, Alazhar University, Eng. College, Cairo, 1993.

[10] Jody D. Priddy, William E. Willoughby, "Clarification of vehicle cone index with reference to mean maximum pressure",Journal of Terramechanics 43(2006)85-96

[11] "Planning and design of roads, airfields, and heliports in the theater of operations, Soils Trafficability", www.globalsecurity.org/military/library

[12] Bolezlay Henzelka, "Theory of Wheeled Vehicles-Part II", Printed Lectures, Bartos, CSSR, Nov. 1964.

[13] H. Ragheb, "Prediction of off road vehicle mobility", MSC thesis, Military Technical College, Cairo, 2007

\section{Nomenclatures:}

$\mathrm{Cl} \ldots \ldots . . . \quad$ Cone index, $\mathrm{N} / \mathrm{m} 2$

$\mathrm{RCl}$....... Rating Cone Index

RI........ Remolding Index

VCl1...... One-pass Vehicle Cone Index

VCl50.... 50-pass Vehicle Cone Index

$\mathrm{Cl} \ldots \ldots \ldots$ Cone index, $\mathrm{N} / \mathrm{m} 2$ 